\title{
Company's management in case of emergency and ecological disaster
}

\author{
Ekaterina Savelieva ${ }^{1,2}$, Marina Danilina ${ }^{1,3,4,5,{ }^{*}, \text { Elena } \text { Kostromina }^{6}, \text { Ivan Kondrashov }}{ }^{2}$, \\ Vadim Blekus ${ }^{2}$, and Yulia Golikova ${ }^{2}$ \\ ${ }^{1}$ Moscow University named after S.Yu. Vitte (MUIV), 115432, Moscow, 2nd Kozhukhovsky proezd, \\ 12 , stroyeniye 1 , Russia \\ ${ }^{2}$ Gzhel State University, 140155 Moscow region, Ramensky district, pos. Electrical insulator, 67 \\ ${ }^{3}$ Research Institute VNII of Labor, Ministry of Labour of Russia, Zemlyanoy Val, 34, 105064 \\ Moscow, Russia \\ ${ }^{4}$ Plekhanov Russian University of Economics (PRUE), Stremyanny per., 36, 117997 Moscow, Russia \\ ${ }^{5}$ Finance University under the Government of the Russian Federation, Leningradsky prosp., 49, \\ 125993 Moscow, Russia \\ ${ }^{6}$ Russian State University of Tourism and Service, 141221 Moscow oblast', Pushkinsky district, dp \\ Cherkizovo, ul. Glavnaya, 99, Russian Federation
}

\begin{abstract}
Emergency is the violation of normal living conditions and activities of people at the facility and a certain territory that arose as a result of an accident, catastrophe, natural disaster, epidemic, as well as the use of modern weapons by the enemy, which led to human casualties, damage to health and the environment, material losses. This article discusses the management of the work of enterprises and organizations in emergency, problems associated with natural emergencies (natural disasters). Emergency management involves the creation of a system consisting of a number of subsystems. The authors analyse the possible ways of solution the problem of the company's management in emergency.
\end{abstract}

\section{Introduction}

Enterprise management is a systematic impact on the work of all its structural elements, the purpose of which is to organize coordinated work and, as a result, make a profit. The goal of enterprise management is to achieve coordinated work of all departments to obtain maximum effect. The essence of enterprise management is to organize this consistency. Due to the fact, that the enterprise is a complex production system, which is based on such components as fixed assets, material, financial and labour resources, the task of management is to use these resources with maximum efficiency. At the exit, it is necessary to obtain a high-quality competitive product that will contribute to the further development of production [1].

Working in emergencies, during the elimination of their consequences, makes serious demands both on the professional training of specialists in the elimination of the consequences of an emergency (military, rescuers, firefighters, dog handlers, doctors,

\footnotetext{
${ }^{*}$ Corresponding author: marinadanilina@yandex.ru
} 
engineers), and on the heads of enterprises and organizations that continue to function during such situations.

Leaders and professionals working in an emergency are exposed to a myriad of stressors. The cost of error in such cases is extremely high. The need to quickly make decisions on which people's lives may depend, work in non-standard conditions with an irregular work schedule and a lack of information are the specifics of work in an extreme situation.

In an emergency zone, the state of people is subject to the general laws of adaptation to a stressful situation. People's susceptibility to stress factors is determined by individual psychophysiological characteristics, the level of stress resistance, and work experience. It is good if a person knows that he can wait (although there are no identical situations - each is special in its own way) [2].

An emergency always disrupts plans, pulls out of the daily rhythm. For those who already have experience working in an emergency situation, this circumstance is not traumatic, but most people usually do not have such experience, and it will certainly become a stressful factor for them. Knowledge of the patterns of mental response to a stressful situation increases the body's tolerance to the effects of stress.

\section{Materials and methods}

On the basis of the content analysis method the authors analyse the possible ways of solution the problem of the company's management in emergency.

Almost any industrial facility has a significant negative impact on the environment. Therefore, ensuring environmental safety is an important task of the WRC. Considering the technological part of the project, one should evaluate it from the point of equipment safety for the environment. The analysis should begin with identifying sources of environmental pollution at the object under consideration. Further, the analysis of the company's emissions into the atmosphere, water, the formation of solid production wastes is carried out. In this case, it is desirable to quantitatively characterize the impact of the object under consideration on the state of the environment.

Emergency is the violation of normal living conditions and activities of people at the facility and a certain territory that arose as a result of an accident, catastrophe, natural disaster, epidemic, as well as the use of modern weapons by the enemy, which led to human casualties, damage to health and the environment, material losses.

Emergency management involves the creation of a system consisting of a number of subsystems. The most important ones are:

- analysis of emergency situations;

- emergency warning;

- localization of emergency situations;

- elimination of consequences;

- development management;

- an integrated distributed database (IRBD).

Emergency analysis system is an information and analytical system that ensures the efficiency of the functioning of subsystems:

- localization and elimination of emergency consequences (typical scenarios of work performance);

- emergency prevention (measures to prevent emergency situations).

In the development of the analysis system, the following main blocks of tasks are distinguished:

- Methods of collecting information about emergency. It is planned to organize several channels for collecting information: press, polling of participants, computer networks, etc. Methods of automated control of the reliability and consistency of information are envisaged. 
- Database of emergency (included in the IRBD) and methods of its maintenance. The database must be developed. It contains the following basic information: time, place (latitude, longitude, nearest settlement), type of situation, power according to the appropriate scale, video, audio, text materials both in the original languages and translated into the national language, duration and methods elimination of the consequences, mistakes and blunders, wasted resources, incurred losses and methods of their calculation, other parameters [3].

Information is loaded into the database in the following ways: manual input of text information from the keyboard, input of text information using scanners and converters, input of graphic information (diagrams, photos) using scanners, input of visual and audio information with its conversion into digital form, input of information using INTERNET databases (Reyter, CNN, etc.). The processed information is stored on the INTERNET server to which there is access (within the limits of authority) from any place for use in normal situations.

- Emergency classification system. It is envisaged to analyze and classify: the causes of the emergence and spread of emergency situations, associated factors (weather, time of day, year, etc.), methods of elimination, etc.

- Methods of analysis of emergency situations. Methods are being developed for the formation and analysis of cause-and-effect relationships, methods for establishing the relationship between different (including and spaced in space and time) factors.

- Methods for developing typical scenarios for localization and emergency response. Methods for generating network diagrams and building plans are determined.

- Methods for the formation of measures to prevent emergencies. Methods of analysis, assessment and selection of measures affecting the elimination of the causes of the emergence and spread of emergencies [4].

The emergency warning system is the most important and is:

- organization (structure, functions, connections, mechanisms, order of interaction, etc.);

- a system of measures to prevent emergencies for different types of technogenic systems;

- a set of methods for monitoring the implementation of established rules and measures of organizations and enterprises;

- a system of technical means to carry out work on the localization and elimination of the consequences of emergencies;

- training.

Organizationally, the emergency warning system consists of regionally distributed control bodies. In parallel with the management bodies, there is also a system of technical means for solving the tasks facing the relevant management body to prevent emergencies (including for work on localization and elimination of consequences). A significant role in the organizational structure is also assigned to enterprises (with their own technical means) that do not belong to the sphere of management of the Ministry of Emergency Situations in normal conditions, but can, if necessary, be involved in performing the relevant tasks for the prevention, localization and elimination of emergencies [5].

Designing an organization involves optimizing the distribution of functions, rights, responsibilities and technical means by levels and regions with the aim of their mobile use and ensuring reliable performance of tasks. Since the development of the technosphere is constantly taking place, a mechanism for adapting the organizational structure of the system to these changes is also necessary.

Industry-specific emergency warning systems (for example, transport, construction, energy, etc.) take an essential place in emergency prevention.

The development of methods for monitoring the effectiveness of such systems, as well as the development of systems for their certification, is urgent.

It is also important to have an effective system for planning and analyzing the functioning and development of the emergency prevention system. 
The system of measures to prevent emergencies involves the development of standard procedures and rules for performing work aimed at improving the reliability of the functioning of man-made systems. For many objects, these measures should be developed in a complex (heat and explosion safety, environmental safety, etc.).

The set of emergency prevention methods provides for a control planning system taking into account the availability of personnel and the complexity (volume) of control procedures, the development of automated methods of direct and indirect control.

It is important to create a remote control and monitoring system for both departmental emergency prevention systems and radiation and chemical pollution. The main functions of such a system are:

- collection of information from geographically distributed sensors of heterogeneous information;

- collection of information from departmental emergency warning systems;

- processing information from sensors and departmental systems and presenting it in the desired form (textual, graphic);

- comparison of actual data with norms (control);

- approximation of the characteristics of pollution in the territory not covered by the sensors;

- forecast of "the spread of pollution as a result of emergency situations under the influence of various factors;

- statistical processing of information on pollution and parameters of departmental systems (in space and time).

- the system of technical means for localizing and eliminating the consequences of emergencies consists of constantly improving systems of machines, equipment, tools, outfit, etc.

The training system is designed to instill the skills and culture of personnel at any facility. It is planned to revise the relevant educational literature, introduce the necessary courses or sections into the existing university programs.

Management system for localization and elimination of emergency consequences. The localization process is aimed at implementing emergency measures in order to contain and suppress the development of emergencies, begins immediately after the onset of an emergency and lasts from several days to several months [6].

In addition to creating an organization and developing plans, it is important that the system has effective subsystems that ensure the implementation of plans. These include subsystems:

- accounting and control of tasks;

- monitoring the progress of liquidation of the consequences of emergency situations;

- regulation of the process of implementation of plans.

The system of accounting and control of the execution of tasks provides:

- accounting of the actual performance of tasks;

- control over the performance of individual works (including document flow) with a reminder to the executors of the deadlines;

- taking into account the occurrence of unforeseen circumstances causing deviations from the planned targets.

The monitoring subsystem allows the management, regardless of location, to have realtime information on the progress of emergency response:

- network schedule with a mark of completed, ongoing, critical work;

- lagging work with an indication of the reasons and culprits;

- available resources and their use;

- forecast of emergencies development. 
The regulation subsystem provides the possibility of implementing the adopted plans and allows:

- choose measures to reduce the impact of destabilizing factors on the plan;

- make adjustments to the plan in case of unforeseen situations.

\section{Results}

Elimination of the consequences of an emergency begins after the completion of the localization stage and can last from several months to several years.

The proposed system should ensure the effectiveness of these works and reduce losses caused by emergencies.

The management system for the localization and elimination of the consequences of emergency situations involves the development of formalized methods for organizing the processes of localization and elimination of consequences, the development of work plans.

This system can significantly speed up the timing of work to localize and eliminate the consequences of emergencies, as well as reduce losses from emergencies.

Elimination of the consequences of emergencies requires the rapid creation of an organizational structure consisting of a headquarters and a large number of enterprises, departments, institutions, local administrations, international organizations, etc. This structure provides for management bodies, work managers in certain areas, the rights and obligations of participants, etc [7].

In addition to the structure, it is necessary to develop work plans, both general and for separate (not predetermined) directions. The plans should provide for the coordination of the work of all involved participants in the elimination of the consequences of emergencies, as well as take into account the available resources (material, human, financial, time, etc.). The quality of plans should be assessed by a set of technical and economic indicators. To increase the reliability of plans, possible scenarios for the development of emergencies are preliminarily worked out. For each of the scenarios, several variants of plans are formed and the choice of the most acceptable in terms of a set of indicators is carried out.

\section{Discussions}

Deterioration of the environment due to technological pressure, an increase in the influence of negative factors on health of the population, increased risk of emergencies and depletion of natural resources and degradation of natural complexes are considered as a threat to environmental safety and sustainable development of regions.

In these conditions, it becomes more and more obvious the need of transition to sustainable development based on the concept aimed at reducing the negative impact on the environment and industrial production on environment while maintaining economic growth of enterprises, which implies a wide distribution of environmentally friendly management space, nature management and environmental protection.

Both in Russia and abroad, new promising research on such issues of environmental management of industrial enterprises as a gradual abandoning traditional command-andcontrol methods and the transition to modern market mechanisms for environmental regulation.

Improving the management of environmental protection can be found in the works of many scientists. They are devoted to the enterprise, however, a try for a certain scientific groundwork, the real mechanism for the practical implementation of the principles of sustainable development at the level of specific enterprises is still in its development. A special aspect is the problem of forming a new culture, which is gaining relevance enterprise 
management based on principles eco-efficiency, implying reduction and prevention the negative impact of production on the surrounding natural environment while increasing financial efficiency its functioning.

Transition to a higher level of environmental management activity in the enterprise requires that the management decisions taken are appropriately oriented tied and grounded. in recent years, addressing environmental problems in industrial production are associated with the introduction of the environmental management system carried out in accordance with the provisions of international standards

\section{Conclusion}

To conclude, all decisions in the emergency response management system are proactive, for which primary attention is paid to forecasting (modeling) the future in order to influence it, and not to act retroactively.

It is important for the system to have powerful, well-organized databases with various information.

The emergency response management system also provides for the development of methods and tools for creating a flexible global computer network (both at the expense of the resources of the Ministry of Emergency Situations and the computer equipment of the contractors) with a variable structure, which allows you to effectively solve management problems.

The software should allow, regardless of the platform, to quickly connect to the databases of individual participants in the work, ensure reliable communication, taking into account access rights, parallelization of computing work, as well as the timely transfer of planned and organizational and administrative documentation to the attention of interested performers. This should be ensured, including with the use of a computer network and electronic signature.

The development management system is designed to ensure continuous improvement:

- the emergency management system itself;

- machine systems for localization and elimination of emergency situations.

The integrated distributed database, which will be developed within the framework of this project, should provide information to the personnel of the Ministry of Emergency Situations (rapid response teams, strategic research services, etc.).

The base should contain the following basic information:

- scientific organizations (with indication of leading specialists) and directions of their activities;

- organizations and enterprises that can be involved in the elimination of the consequences of emergencies (ATP, utilities, fire departments, etc.);

- a list of funds available to organizations and enterprises and which can be used when carrying out work to eliminate emergencies.

The composition of information for each direction is detailed in the course of work.

The base must be distributed. Each region accumulates and keeps up to date all the necessary information. To ensure the reliability of the information, a powerful system for controlling the input information is provided.

Databases of higher authorities have information common to their regions. Information transfer is carried out via dial-up telephone channels, incl. and using INTERNET. Data access is subject to access rights.

To simplify the search for the necessary information, a powerful system of navigation through the databases and selection of information for complex queries (including those that are not predefined) is provided. 


\section{References}

1. Energy Management, A comprehensive guide to controlling energy use, Carbon Trust (2013)

2. Federal Law of December 21, 1994 N 68-FZ "On the protection of the population and territories from natural and man-made emergencies"

3. V.D. Zazulinsky, Safety of life in emergency situations (2003)

4. E.A. Arustamov, Life safety (M .: Dashkov i K, 2001)

5. N.G. Osukhova, Psychological assistance in difficult and extreme situations (M.: Academy Year: 2007)

6. N.N. Pukhovsky, Consequences of emergency situations (M .: Academic project, 2000)

7. EMERCOM, official site, http: //www.mchs.gov.ru/ [Date of addressing: 15.02.2021]

8. L. Pushkareva, M. Pushkarev E3S Web of Conferences 135, 04070 (2019) doi:10.1051/e3sconf/201913504070 